\title{
Fósiles de ballenas prehistóricas en el desierto: El Museo de Sitio de Sacaco
}

\author{
Prehistoric whale fossils in the desert: The Site Museum of Sacaco
}

${ }^{1}$ Marilda Dávila Rivera

${ }^{2}$ Mario Gálvez Marquina

ORCID: 0000-0002-9077-0740

ORCID: 0000-0002-8948-55-20

\section{RESUMEN}

Los desiertos de los departamentos de Arequipa e Ica en Perú estaban bajo el mar durante el Neógeno. En esa época, el incremento de la flora marina en la región produjo el desarrollo de una gran variedad de especies que convirtió al mar de la costa peruana en uno de los siete más peligrosos del mundo. Como testimonio de la vida de esos años están los fósiles de ballenas que se puede encontrar en el Museo de Sitio de Sacaco, ubicado en el distrito de Bella Unión de la provincia de Caravelí del Departamento de Arequipa. Lamentablemente, la falta de presupuesto para mantener este valioso patrimonio natural ha puesto en peligro la conservación de los dos fósiles que se exhiben en el museo; uno de ellos, incluso, se encuentra al aire libre y expuesto al clima costero. El yacimiento de fósiles de Sacaco es uno de los más ricos del mundo y su adecuada preservación puede poner al Perú dentro los lugares más importantes para la paleontología mundial.

Palabras Claves: Fósiles marinos, museo de Sacaco, neógeno.

\section{ABSTRACT}

The desert of the departments of Arequipa and Ica in Peru were under the sea during the Neogene. At that time, the increase in marine flora in the region led to the development of a great variety of species that made the sea of the Peruvian coast one of the seven most dangerous in the world. As a testimony of the life of those years are the whale fossils that can be found in the Site Museum of Sacaco located in Bella Unión district of the Caravelí province of the department of Arequipa. Unfortunately, the lack of budget to maintain this valuable natural heritage has jeopardized the conservation of the two fossils that are exhibited in the museum, one of them even being outdoors and exposed to the coastal climate. The fossil site of Sacaco is one of the richest in the world and its proper preservation can put Peru in the most important places for paleontology in the world.

Keywords: Sacaco Museum, marine fossils, Neogen.

\footnotetext{
${ }^{1}$ Universidad Alas Peruanas. Tacna-Perú. E-mail: marilda_angelica01@hotmail.com

${ }^{2}$ Doctor en Educación, Magíster en Gestión Empresarial, Comunicador Social y Abogado. E-Mail: mariogalvez110@gmail.com
}

Presentado: 31/01/19, Aprobado: 25/09/19 


\section{INTRODUCCIÓN}

En el distrito de Bella Unión de la provincia de Caravelí del Departamento de Arequipa se halla el Museo de Sitio de Sacaco, uno de los lugares más reconocidos en la paleontología peruana. El paleontólogo peruano, R. Salas (2011), describe el Desierto de Sacaco como uno de los yacimientos de fósiles marinos más importantes del mundo, no solo por la cantidad que se puede hallar, sino por la variedad de especies como ballenas, delfines, focas, cachalotes, cocodrilos, aves, entre muchas más que vivieron en el lugar durante el Neógeno. Durante ese periodo, parte del actual desierto arequipeño, incluido Sacaco, estaba cubierto por un mar de poca profundidad, lo que permitió el surgimiento de innumerables especies que, al morir, quedaron enterradas en el lecho marino.

La abundante fauna marina que se desarrolló en el Neógeno sudamericano se puede observar en la variedad de fósiles marinos de la zona de Ocucaje (Ica) y Sacaco (Arequipa), desiertos considerados como unos de los yacimientos paleontológicos de especies marinas más ricos del mundo (Salas, 2015).

Los cadáveres pudieron conservarse debido a la acumulación de sedimentos que se depositaron en el fondo del marino y que ha permitido que, en la actualidad, podamos ver y tocar los fósiles de las especies marinas que vivieron en el mar de Arequipa hace cinco millones de años.

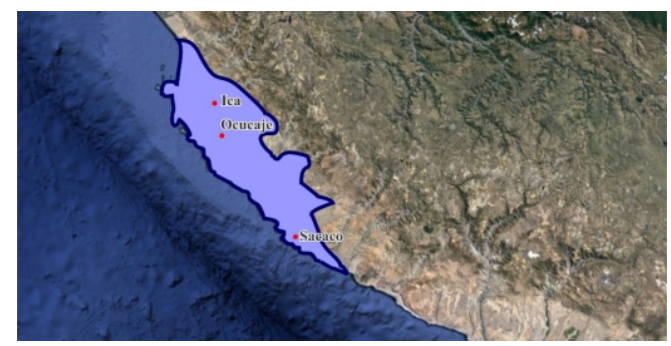

Figura 1. Ocucaje y Sacaco bajo el mar durante el Neógeno, tomado de Salas (2015).

Los ricos yacimientos han permitido que los paleontólogos peruanos Pujo y Salas (2004) descubrieran especies extintas como el Megatherium del pleistoceno en Sacaco y Tres Ventanas en Arequipa.
A pesar de ser un valioso yacimiento de fósiles a nivel mundial, el museo de sitio no cuenta con los recursos necesarios para conservar y mantener los restos fosilizados de las especies de esta zona paleontológica. Actualmente, el lugar viene siendo investigado por paleontólogos de distintas universidades del país quienes, en varias ocasiones, han dado a conocer la necesidad de estudiar la zona con el despliegue de mayores recursos.

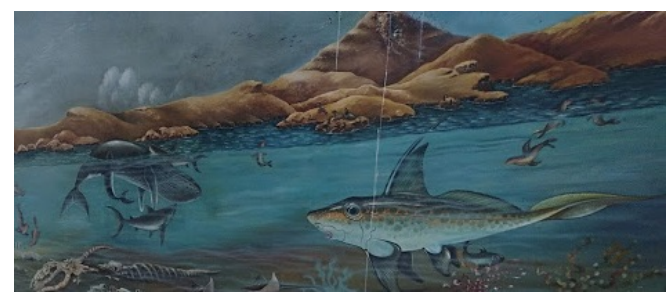

Figura2. Mural en el Museo de Sitio de Sacaco.

\section{PRIMEROS INDICIOS DE FÓSILES EN SACACO}

El término fósiles provienen del latín fossilis (que se extrae excavando) y se refiere a aquellos restos o rastros que permiten conocer cómo se vivió en la antigüedad. Es así, que los esqueletos, conchas, plantas o huellas, entre otros sufrieron diferentes procesos físicos, químicos y biológicos que posibilitaron su conservación a lo largo de los años. De esta forma, los fósiles son una especie de fotografía en tres dimensiones que muestran la forma de vida de especies extintas.

Un fósil surge por la substitución, de las moléculas pertenecientes a los tejidos orgánicos sólidos como huesos, caparazones, maderas entre otras, por elementos minerales que, virtualmente, las trasforman en rocas, logrando así el proceso que se conoce como la fosilización (Perea, 2018). La ciencia encargada de estudiar a los fósiles es la paleontología, su estudio en el Perú tiene como uno de sus mayores representantes a Antonio Raimondi, padre de la paleontología peruana. De acuerdo a lo publicado por el Museo Raimondi (2018), los primeros indicios que se tienen sobre el rico yacimiento de fósiles marinos en el desierto arequipeño, fue expuesto, precisamente, por el sabio Raimondi, quien, en el año de 1863, viaja por las quebradas de Sacaco y registra diversos fósiles 
de origen marino, entre los que identifica cetáceos (ballenas) y moluscos que corresponderían a especies extintas. En 1911, Carlos Lisson, publica el Tomo VI de la serie $E l$
Perú, titulado Paleontología Peruana, en el que expone los hallazgos de la colección de fósiles encontrados por Raimondi.

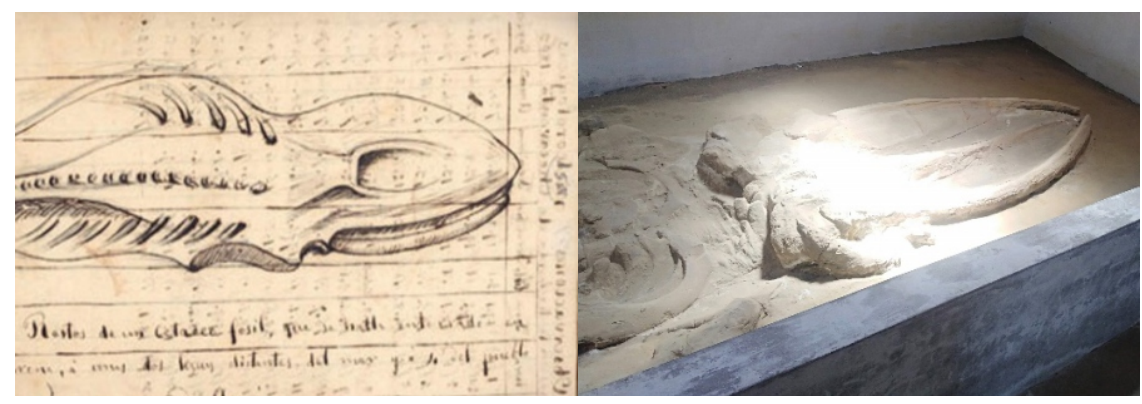

Figura 3. A la Izquierda: Esqueleto fosilizado de Acarí (cerca de Sacaco) publicado por Antonio Raimondi en 1878. A la derecha: Esqueleto fosilizado en el Museo de Sitio de Sacaco encontrado por Roque Martin Buey.

\section{ELMUSEO}

El museo de sitio de Sacaco se encuentra ubicado a los $15^{\circ} 32^{\prime} 40.3^{\prime \prime}$ latitud Sur y los 7443'55.6" longitud Oeste, a $12.5 \mathrm{~km}$ del distrito de Bella Unión. Este poblado su ubica a los márgenes de río Caravelí del Departamento de Arequipa. El acceso al museo no se realiza por una carretera asfaltada, sino que para llegar se debe ingresar por una carretera afirmada a la altura del kilómetro de 547 de la Panamericana Sur. La ruta, a pesar de sus condiciones, permite el ingreso de vehículos livianos que deben recorrer unos dos kilómetros.

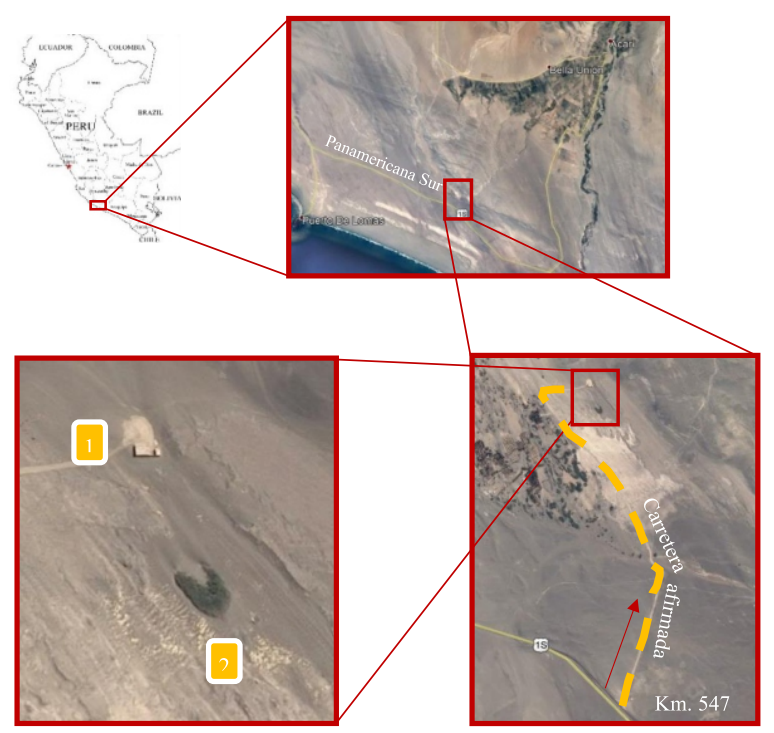

Figura 4. Ubicación del Museo de Sitio de Sacaco. 15³2'40.3" S; 7443'55.6" O. 1. Exposición de fósiles en ambiente cerrado. 2. Exposición de fósiles al aire libre. Fuente: Google Earth 2019 CNES/Airbus. 
El museo de sitio es una filial del Museo de Historia Natural de la Universidad Nacional Mayor de San Marcos, consta de un ambiente cerrado construido por Hans Jakob Siber a finales de la década de los 80 , en el que se puede encontrar el fósil de una ballena de 10 metros de largo a la que los lugareños nombraron como "Roque" (Figura 5). Este fósil fue descubierto por Roque Martin Buey, un migrante vasco, que se asentó en la zona y cuyos descendientes continúan hasta hoy siguen conservando la ballena fosilizada. El fósil corresponde a un misticeto (Mysticeti) conocido como ballena barbada que vivió a mediados del Mioceno medio y Plioceno inferior. Además, en el lugar también se exhiben otros fósiles como: conchas marinas de más de $10 \mathrm{~cm}$ de diámetro, tobas con impresiones de la paleoflora y mandíbulas de tiburones recientes (Figura 7).

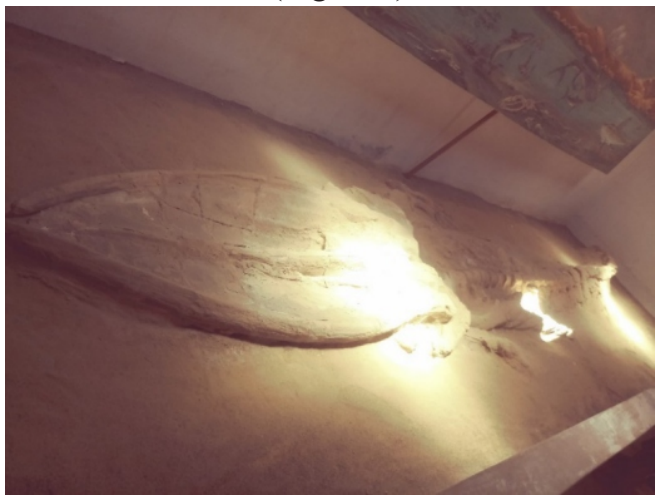

Figura 5. Fósil marino de 5 millones de años aproximadamente.

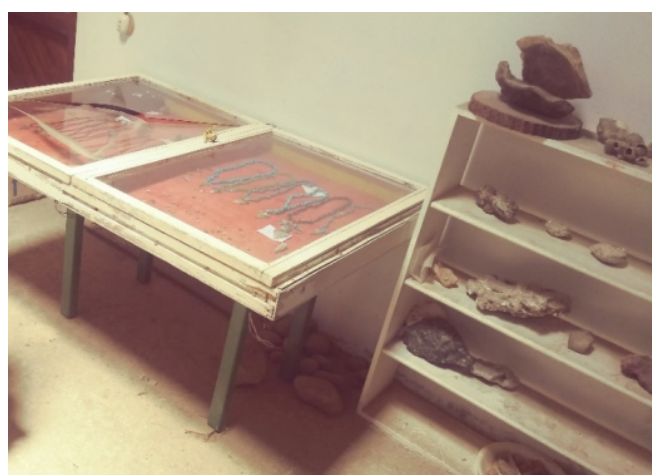

Figura 6. Muestras del Museo de Sitio Sacaco. 1. Conchas marinas fosilizadas del Mioceno medio y Plioceno inferior. 2. Collares hechos con dientes de tiburón. 3. Rocas volcánicas con registro de flora de la época.

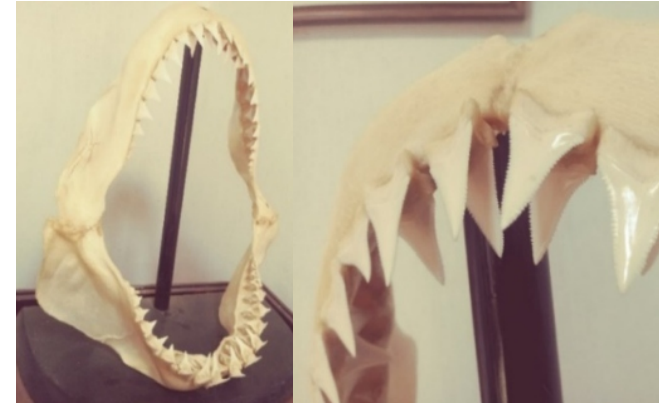

Figura 7. Mandíbula de tiburón reciente expuesto en el Museo de Sitio de Sacaco.

En un segundo sitio del museo, a cien metros de la construcción realizada por Hans Jakob, se puede observar otro fósil de ballena barbada a la intemperie. El fósil, a pesar de que no se halla en las condiciones más adecuadas de preservación, permite valorar el importante patrimonio natural que el Perú tiene en el desierto de Arequipa y que debe ser investigado en su real magnitud, pues las especies que se pueden encontrar podrían aportar grandes descubrimientos tanto a la paleontología nacional como a la mundial.

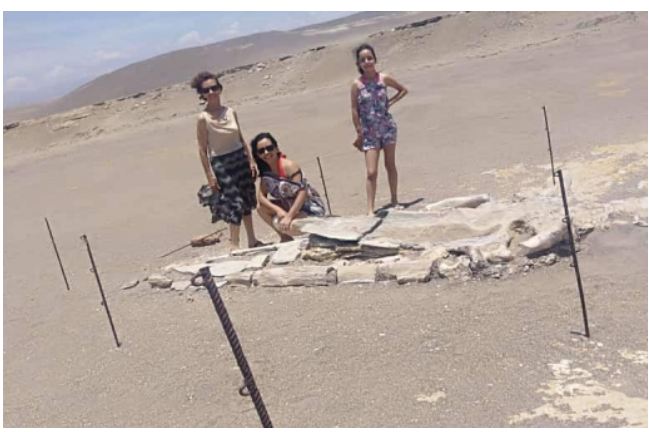

Figura 8. Fósiles de ballena expuestos a la intemperie en el Museo de Sitio de Sacaco.

\section{CONCLUSIONES}

El Museo de Sitio de Sacaco representa uno de los patrimonios naturales más importantes con los que cuenta el Perú, sin embargo, no cuenta con los recursos necesarios para preservar los fósiles que tiene en exhibición.

La riqueza de la fauna marina desarrollada durante el Neógeno (23.03-5.333) puede ser apreciada en el desierto de Sacaco debido a que 
esta zona se hallaba bajo el mar en aquellos años.

Desde las investigaciones de Antonio Raimondi a la actualidad, han sido pocos los esfuerzos por investigar este importante yacimiento de fósiles marinos, los cuales podría convertir al Perú en uno de los lugares más importantes para la paleontología marina.

\section{REFERENCIAS}

Museo Raimondi. (2019). Paleontología. $\mathrm{O}$ b t e n i d o d e http://www.museoraimondi.org.pe/es/ contenido/21/paleontologia

Perea, D. (2018). Fundamentos de paleontología. Montevideo: Universidad de la República Uruguay.
Pujos, F., \& Salas, R. (2004). A new species of Megatherium (Mammalia: Xenarthra: Megatheriidae) fron the pleistocene of Sacaco and Tres Ventanas, Perú. Journal Palaeontology, Vol. 47, 579604.

Salas, R. (2011). Exhibición paleontológica: el mundo perdido de Sacaco y Ocucaje. Bulletin de l'Institut français d'études andines, Vol. 40(Nro. 1), 221-223.

Salas, R. (2015). Riqueza paleontológica dela costa peruana. Obtenido de http://www2.congreso.gob.pe/sicr/co misiones/2013/com2013cultura.nsf $/ / \mathrm{p}$ ubweb/1B7618CBC82C6CF305257C 430074203D/\$FILE/OCUCAJE_CON GRESO.PDF 